\title{
New Perfluorocarbon System for Multilayer Growth of Anchorage-Dependent Mammalian Cells
}

BioTechniques 32:142-151 (January 2002)

\section{Rappaport, Y. Rensch, M. Abbasi, M. Kempe, C. Rocaboy ${ }^{1}$, J. Gladysz ${ }^{1}$, and E.M. Trujillo \\ University of Utah, Salt Lake City, UT, USA and ${ }^{1}$ Universitaet Erlangen-Nuernberg, Erlangen, Germany}

\section{INTRODUCTION}

A major problem in tissue culture is providing anchorage-dependent cells with the oxygen needed for optimal growth. Measurements with oxygen microelectrodes have shown that, with all cell lines tested, the oxygen in the medium at confluency is less than that required to maintain their normal rates of respiration (16). In the case of Hep G2 cells, the oxygen in the medium used to replenish the cultures was found to drop from 140 to less than $1 \mathrm{~mm} \mathrm{Hg}$ within 1 $\mathrm{h}$ after replenishment (24). The metabolism and synthetic capacity of the cells would have been restricted long before they reached confluency.

The hypoxic condition of the cells in culture has been attributed to the fact that the diffusion of oxygen in growth media is so slow that it cannot reach the cells growing at the bottom of culture dishes at the rates needed to replenish the oxygen consumed. Oxygen is 15-20 times more soluble in perfluorocarbons (PFCs) than in aqueous medium (23). PFCs have been used as artificial blood cells to provide oxygen during surgery and to improve ATP levels in excised tissue (13). Keese and Giaever $(11,12)$ have shown that cells could be grown on the surfaces of PFCs. However, it was found that the cells did not grow directly on the PFC but on a film of denatured protein desorbed from the serum used in the medium. They also showed that polar groups contaminating the PFC played an important role in the formation of the films $(6,11)$. These findings provided the basis for our investi- gations, which have been directed toward developing protein-covered PFC substrata to improve oxygenation and to increase the growth of anchorage-dependent cells.

We have previously reported the development of a PFC-based substratum for the growth of Hela cells $(21,22)$. The substrata were made by coating perfluorodecalin with perfluoroalkylated gelatin. These substrata supported good adhesion while providing oxygen directly to the cell-substratum interface and to the medium. Hela cells were found to grow on this novel substratum into a tissue-like structure of more than 19 layers of cells, compared to the 2-3 layers grown in tissue culture dishes (21). It was also found that the number of layers that could be grown was determined by the amount of oxygen available by diffusion from the PFC. Because Hela cells do not synthesize a marker protein, it was not possible to determine whether cell-specific functions would be maintained during multilayer growth.

Hep G2 cells derived from a heptoblastoma have retained the capacity to synthesize many liver-specific proteins (3). They are strongly contact inhibited when they are grown in polystyrene tissue culture dishes or flasks. Here, we report a revised PFC substrata system that supports the multilayer growth of Hep G2 cells that continue to secrete albumin.

The substrata are made by coating perfluorotrihexylamine with collagen type 1 . The good multilayer growth of Hep G2 cells also depends on two additional technical innovations. The first 
was synthesizing a perfluoroaldehyde for coupling collagen and other matrix factors to PFCs. We also fabricated a multiwell plate in which the wells are provided with collagen-coated FC-71 substrata and the walls are made of silicon tubing. Because silicon is very permeable to oxygen, this design promotes the replenishment of oxygen as the cells consume it. Hep G2 cells grow on these substrata to more than 10 layers of cells while maintaining a high rate of albumin secretion. This new tissue culture system, called the controlled oxygenation perfluorocarbon system (COPS), makes it possible to investigate the metabolism and behavior of cells in cultures where, even at high densities, the demand for oxygen is met by the oxygen provided. In contrast, the oxygenation of cells growing in polystyrene dishes may decline as a result of increased density or time. This can limit growth and jeopardize the interpretation of the results.

\section{MATERIALS AND METHODS}

\section{Cell Culture}

Hep G2 cells were obtained from ATCC (Manassas, VA, USA). They were carried as stock cultures in DMEM supplemented with $1 \mathrm{mM}$ sodium pyruvate, $0.1 \mathrm{mM}$ nonessential amino acids, $10 \%$ FBS (ATCC), penicillin (100 $\mathrm{U} / \mathrm{mL})$, and streptomycin $(100 \mu \mathrm{g} / \mathrm{mL})$. This medium is referred to as $\mathrm{DMEM}^{+}$. Collagen type 1 and epidermal growth factor were obtained from Becton Dickinson (Franklin Lakes, NJ, USA). All other biochemicals were obtained from Sigma (St. Louis, MO, USA). The 35$\mathrm{mm}$ diameter tissue culture dishes and 24-well tissue culture plates were Corning products (Corning, NY, USA). The stock cultures were passaged at confluency by trypsinization $(0.25 \%$ trypsin and $0.03 \%$ EDTA) and split 1:4 every 5-7 days. The trypsinized suspensions of stock cultures contained clumps and were not suitable for quantitative growth studies. These were done using suspensions prepared by trypsinizing one of the subcultures 2-3 days after passage. This provided single-cell suspensions with a viability greater than $99 \%$, as determined by trypan blue exclusion.
The growth was determined by fluorometric assay of DNA using Hoechst stain no. 33258 and calf thymus DNA as the standard (15). The number of cells in the cultures was determined by comparison with a calibration curve for cell number versus DNA made from many trypsinized suspensions.

Albumin secretion was assayed by sandwich ELISA using a monoclonal anti-human antibody, an HRP-conjugated polyclonal goat anti-human antibody (Bethyl Laboratories, Montgomery, TX, USA), and TMB peroxidase stain (Kirkegaard \& Perry Laboratories, Gaithersberg, MD, USA). The development of color at $650 \mathrm{~nm}$ was maximal after $20 \mathrm{~min}$, at which time the reaction was stopped by the addition of phosphoric acid to give a final concentration of $0.1 \mathrm{M}$. The yellow color that developed was read at $450 \mathrm{~nm}$ using a Spectronic $^{\mathrm{TM}} 20$ (Bausch \& Lomb, Rochester, NY, USA). Samples from the wells were diluted $1000 \times$ and assayed in each experiment against a calibration curve made with human albumin (Sigma) over the range of $0-400 \mu \mathrm{g} / \mathrm{mL}$.

\section{Experimental Chemical Engineering}

Perfluorotrihexylamine (FC-71 ${ }^{\mathrm{TM}}$ ) was obtained from Lancaster (Windham, NH, USA) and as generous gift from 3M Company (St. Paul, MN, USA). The 3-(perfluorooctyl)propanol was obtained from Flourochem USA (West Columbia, SC, USA). Lexan was obtained from the local plastics supply store. The model 3450 Phillips SBC soldering iron was obtained from MCM Electronics (Centerville, OH, USA).

Glass discs were cut to the size specified by Precision Scientific Company (San Francisco, CA, USA). The model 200 Branson ultrasonic cleaner $(120 \mathrm{~V}$, $50-60 \mathrm{~Hz}, 40 \mathrm{~W}$ ) was obtained from Fisher Scientific (Pittsburgh, PA, USA). Silicon tubing and micro-valves were obtained from Cole-Parmer (Vernon Hills, IL, USA). All other chemicals were obtained from Aldrich Chem ical (Milwaukee, WI, USA).

\section{Fabrication of a Gas-Permeable Multiwell Plate}

A series of plates to be used with PFC substrata were designed, built, and evaluated for multilayer growth of Hep G2 cells. Figure 1 shows the fifth generation of a suitable multiwell plate (COPS plate 5). The plates are made with Lexan, which is transparent and can be sterilized by autoclaving. It was bought in 1/4-in-thick and 1/8-in-thick sections. The cutting of the plastic and the drilling of the holes were done in the departmental machine shop.

The COPS plate 5 is $3 \times 3$ in and 1.5 in high. The bottom plate is made with 1/8-in-thick Lexan, and the four side plates, $3 \times 13 / 8$ in each, are made with 1/4-in-thick Lexan. The bottom plate has been drilled with nine holes (diameter $0.624 \pm 0.025 \mathrm{in}$ ). The bottom and side walls are soldered together using the Phillips soldering iron. Cements that are recommended for Lexan cannot be used because they have been found to leave residues that are toxic to the cells. A top lid $(3.5 \times 3.5$ in $)$ is made with $1 / 8$-in-thick Lexan, to which four strips of the 1/8-in-thick Lexan (3 1/4-in-long and 1/4-in-wide) are soldered at its edges so as to fit over the growth chamber, preventing the contamination and escape of gases. Two holes in opposite walls, 1 in from the bottom, have been drilled to serve as ports for the inlet and outlet of gases. These can be fitted with micro-valves and attached to different gas mixtures for studies on the effect of oxygen concentrations on growth. Left open in a $5 \% \mathrm{CO}_{2}$-air incubator, the cultures are maintained at $20 \%-21 \%$ oxygen.

The nine holes in the bottom of the plate are converted into wells for grow ing cells as follows: gas-permeable, peroxide-treated silicon tubing (i.d., 5/8 in, with $1 / 8$-in-thick walls) is washed with alconox, rinsed with deionized water, and cut into 1.5-in-long strips. It is important that the cuts are straight and even. Working from the top of the chamber, a tube is slipped into one of the holes in the bottom plate so that 2-3 $\mathrm{mm}$ of tubing protrudes beyond the bottom surface of the plate. Working from the bottom of the plate, an optically flat glass disc $(1.32 \mathrm{~cm} \pm 0.025 \mathrm{~mm}$ in diameter and $1.66 \mathrm{~mm} \pm 0.025 \mathrm{~mm}$ in thickness) is inserted perpendicularly into the tube to a depth so that, when pushed sideways, one edge is flush with the inside bottom rim of the tube. The disc is then pushed flat by gently tap- 
ping it down from inside the tube with a plastic rod. The glass disc with its silicon rim is then pushed, by thumb, up into the hole so that both disc and silicon rim are flush with the bottom of the plate. The procedure takes advantage of the fact that silicon can be both stretched, allowing the insertion of the disc into the slightly smaller orifice of the tube, and compressed so that the tube with the disc fits into the hole in the bottom of the plate to provide leakproof wells. The assembly of the nine windows in one plate takes about $5 \mathrm{~min}$.

The dimensions of the plate and the number of wells can be varied. However, the size specified for the holes in the bottom of the plate must be strictly met to have leak-proof wells after the silicon tubes have been inserted. PFCs are optically clear so that the cells in the wells can be can be observed during growth using an inverted phase microscope at $100 \times$ magnification. However, because silicon tubing is not perfectly straight, even slight bending alters the light path. To hold the tubes straight, a retainer plate $(23 / 4 \times 23 / 4$ in $)$ made with $1 / 8$ in-thick Lexan, with nine holes of the same diameter as the bottom plate, has been soldered inside the growth cham ber at 1 and $11 / 2$ in from the bottom.

\section{Synthesis of Perfluoroaldehyde}

In the first studies done with Hela cells (21), gelatin was perfluorinated with perfluorooctypropylisocyanate (gift of duPont de Nemours, Wilmington, DE, USA). This required using organic solvents that could alter the conformation of matrix factors. It also took several days to prepare one substratum. We investigated the possibility of bonding matrix factors to PFC surfaces by coupling them using cyanoborohydride to a perfluoroaldehyde (PF-aldehdyde). Because an appropriate PF-aldehyde was not commercially available, we synthesized one.

The overall synthesis involves converting 3-(perfluorooctyl)propanol to an aldehyde using the Dess-Martin oxidizing reagent. This was prepared according to the revised procedure of Ireland and Longbin (7) as follows: working in a chemical hood, $42 \mathrm{~g} 2$ iodobenzoic acid in $365 \mathrm{~mL} 0.73 \mathrm{M}$ sulfuric acid is oxidized by $\mathrm{KBrO}_{3}(38$ g) to the hydroxyiodinane oxide "com pound 2". The reaction is started at $55^{\circ} \mathrm{C}$, gradually raised over $30-40 \mathrm{~min}$ to $65^{\circ} \mathrm{C}$, and maintained at $65^{\circ} \mathrm{C}$ for 3 h. It is washed with water and then ethanol under vacuum filtration. Crystals $(40 \mathrm{~g})$ are dissolved in $400 \mathrm{~mL}$ acetic anhydride containing $0.5 \% \mathrm{p}$ toluene sulfonic acid and heated with stirring at $80^{\circ} \mathrm{C}$ for $2 \mathrm{~h}$. The Dess-Martin reagent precipitates out with a yield of $90 \%$. The entire synthesis takes about $5 \mathrm{~h}$ and should be done without interruption because compound 2 has been reported to explode if stored. The aldehyde is then prepared as follows: $0.67 \mathrm{~g}$ Dess-Martin reagent dissolved in $20 \mathrm{~mL}$ distilled methylene chloride is added to $2 \mathrm{~g} \mathrm{3-(perfluoroctyl)} \mathrm{propa-}$ nol, and the mixture is stirred for $1 \mathrm{~h}$ or more at room temperature in an atmosphere of nitrogen. Ether $(20 \mathrm{~mL})$ is added, followed by $75 \mathrm{~mL}$ water saturated with $\mathrm{NaHCO}_{3}$ and a 7-fold excess of sodium thiosulfate. The mixture is stirred until two clear layers separate. The aqueous layer is removed and the organic layer washed with another 75 $\mathrm{mL}$ water saturated with sodium bicarbonate. The aqueous layers are com bined and washed with ether. The com bined organic phases are dried with anhydrous magnesium sulfate, then filtered, and evaporated under reduced pressure. The PF-aldehyde is purified by distillation using a water-jacketed,

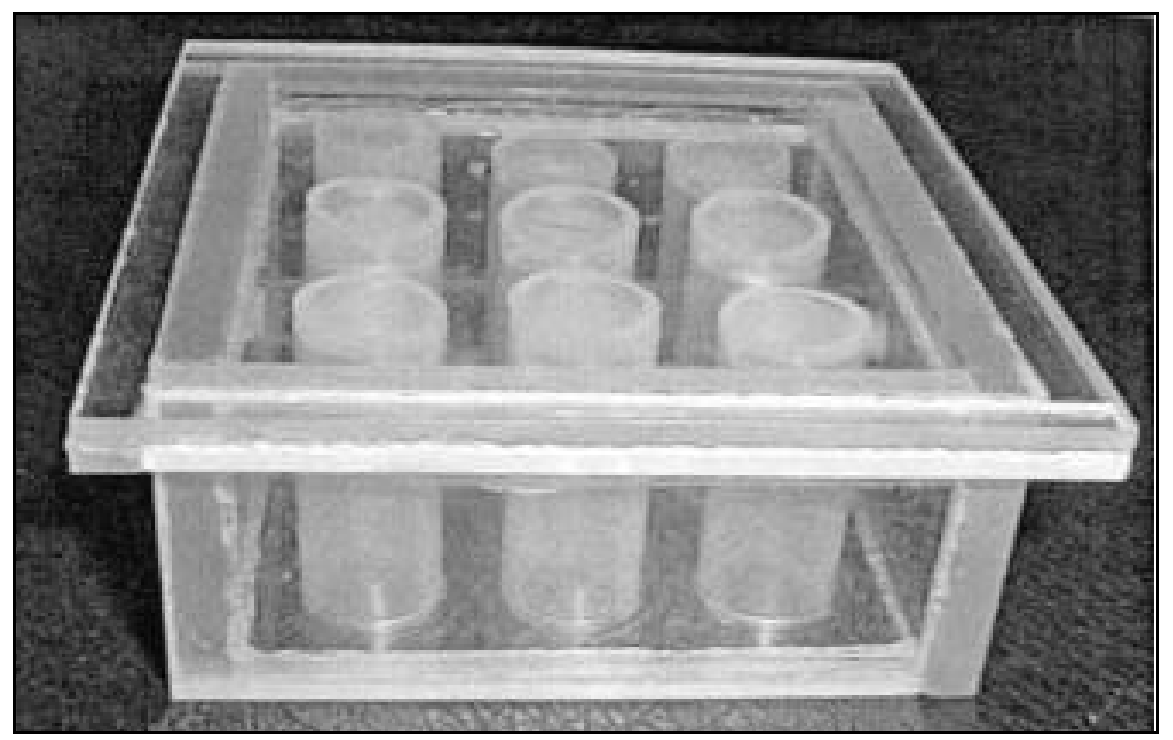

Figure 1. Multiwell plate (COPS plate 5) for tissue culture studies with cells under constant rates of oxygenation. short-path distillation head (Fisher Scientific) while heating the bulb with a heat gun set at $900^{\circ} \mathrm{C}$. The yield of the aldehyde (e.g., $\mathrm{Pf} 8-\mathrm{CH} 2 \mathrm{CH} 2 \mathrm{CHO}$ ) is from $70 \%$ to $80 \%$.

This PF-aldehyde is very stable and has been kept for more than six months at $20^{\circ} \mathrm{C}$ without any change, as determined by nuclear magnetic resonance spectroscopy. Preliminary assays showed that in solution using cyanoborohydride, it perfluorinated $86 \%$ $90 \%$ of the free amino groups on gelatin. However, this involved adding gelatin to the PF-aldehyde dissolved in tetrahydrofuran, which could alter the conformation of a matrix factor, preventing the optimal adhesion of cells when used to coat the PFC. A twophase method for coupling collagen and other matrix factors was developed to maintain, as much as possible, their normal conformation and the optimal adhesion of cells to PFC substrata.

\section{Preparation of Collagen-Coated Substrata}

The PF-aldehyde is mixed with FC71 using ultrasound. This results in the eight perfluorinated carbon tails anchored in the PFC, leaving the aldehyde head groups arrayed at the interface. These are then coupled using cyanoborohydride to the free amino groups on collagen or other matrix factors dis- 
solved in aqueous salt solutions. The concentration of both the PF-aldehyde mixed with FC-71 and the matrix factor in the coupling step was found to be critical and different for the different factors that have been tested. It was also found that better substrata were formed when the PFC had been pretreated for $30 \mathrm{~min}$ with ultrasound using the Branson 200 ultrasonic cleaner. Keese and Giaever $(6,11,12)$ reported that the growth of cells on PFC surfaces depended on the pre-sonication of the PFC. They considered this to be due to the production of surface polar groups. In our system, the ostensible effect of the ultrasound is that it releases gases from micro-bubbles in the PFCs, which prevents bubbles from forming in the substrata after the cells have been seeded. However, the effects of treatment with ultrasound are not completely understood. The preliminary treatment with ultrasound can be done on a large volume of FC-71 and stored at room temperature.

The substrata for the nine wells of a COPS plate 5 are prepared in three steps. The volumes and amounts that are given result in each well (growth area, $1.21 \mathrm{~cm}^{2}$ ) receiving $134 \mu \mathrm{g} \mathrm{PF}$ aldehyde and $50 \mu \mathrm{g}$ collagen type 1 . This ratio has been found to be optimal for multilayer growth of Hep G2 cells.

(i) A stock solution of the PF-aldehyde $(30 \mathrm{mg} / \mathrm{mL})$ is dissolved in FC-71. A volume of $0.055 \mathrm{~mL}$ of this solution is added to $6.45 \mathrm{~mL}$ pretreated FC-71 in a 30-mL NALGENE ${ }^{\circledR}$ (Fisher Scientific) bottle. The mixture is treated with ultrasound for 25 min using the Branson ultrasonic cleaner and then filtered through a $0.22-\mu \mathrm{m}$ filter (Millipore, Bedford, MA, USA). A volume of 0.7 $\mathrm{mL}$ of the mixture is then carefully pipetted into each of the wells in a COPS plate 5 that has been autoclaved and dried. The mixture automatically reorients so that the aldehyde head groups are at the PFC-air interface.

(ii) A stock solution of $0.4 \mathrm{M}$ boric acid containing $2.0 \mathrm{~g} / \mathrm{L}$ sodium cyanoborohydride is adjusted to $\mathrm{pH} 7.4$ with $1 \mathrm{M} \mathrm{HCl}$. This stock solution can be kept for several weeks stored at $4^{\circ} \mathrm{C}-8^{\circ} \mathrm{C}$. Just before preparing the substrata, the stock solution is diluted 0.08:1 in 0.4-M boric acid, $\mathrm{pH} 9.0$, and the $\mathrm{pH}$ is adjusted to 4.0 with $\mathrm{N} \mathrm{HCl}$ and then sterilized by filtration through a $0.22-\mu \mathrm{m}$ sterile filter. The adjustment of the cyanoborohydride-boric acid solution to $\mathrm{pH} 4.0$ should be done just before the preparation of the substrata. A volume of collagen type 1 (in $0.02 \mathrm{M}$ acetic acid) is added to this cyanoborohydride-borate solution to give 72 $\mu \mathrm{g} / \mathrm{mL}$ collagen. A volume of $0.7 \mathrm{~mL}$ solution is added to each well on top of the $0.7 \mathrm{~mL}$ PF-aldehdye-FC-71 mixture added in the first step. The plate is incubated at $37^{\circ} \mathrm{C}$ for $2-3 \mathrm{~h}$.

(iii) As the collagen solution is aspirated from the wells, one should take care to leave a small volume so as to not disturb the substrata. Residual collagen and cyanoborohydride are removed by rinsing three times with 1-1.5 mL 0.01 $\mathrm{M}$ acetic acid, followed by two rinses with sterile water. It is convenient to add a $\mathrm{pH}$ indicator (phenol red, $3 \mathrm{mg} / \mathrm{L}$ ) in the rinse solution to be able to see the substrata-rinse solution interface. The substrata are then covered with $1 \mathrm{~mL}$ nutrient medium containing $10 \%$ serum and $2.2 \mathrm{~g} / \mathrm{L}$ $\mathrm{NaHCO}_{3}$ and incubated overnight in a $5 \% \mathrm{CO}_{2}$-air incubator at $37^{\circ} \mathrm{C}$ to anneal the substrata and equilibrate with the gases. The medium is aspirated, and the wells are ready to be seeded with cells. If not used immediately, then they can be left covered with serum-supplemented medium and kept at room temperature until needed.

Figure 2 shows the arrangement of substrata, cells, and medium in a well of COPS plate 5 when assembled for culture. The cells are growing inside a segment of silicon tubing that has been closed at the bottom with a glass window. The glass bottom is covered with a thin layer of a mixture of PFC and PF-aldehyde whose top surface has been coated, as described earlier, with a monolayer of collagen. Cells adhere to and are cultured on this collagen under an overlay of 1-2 mL medium. This design provides a situation in which all of the elements of the culture (e.g., the PFC substrata, cells, and medium) are provided with a high and uniform level of oxygen by diffusion through the silicon walls from air.

\section{RESULTS}

DMEM supplemented with $10 \%$ FBS has been widely used for studies with Hep G2 cells. It was considered that, although this supports the indefinite propagation of cells as monolayers, it might not be adequate to support the growth of cells in multilayers. A preliminary series of experiments were done in which various hormones, growth factors, and metabolites were screened to detect any that might promote multilayer growth. The procedure used was to seed cells in 35-mm tissue culture dishes at a low density known to be limiting (initially 5000 cells $/ \mathrm{cm}^{2}$ ) in $\mathrm{DMEM}^{+}$(e.g., DMEM containing 1

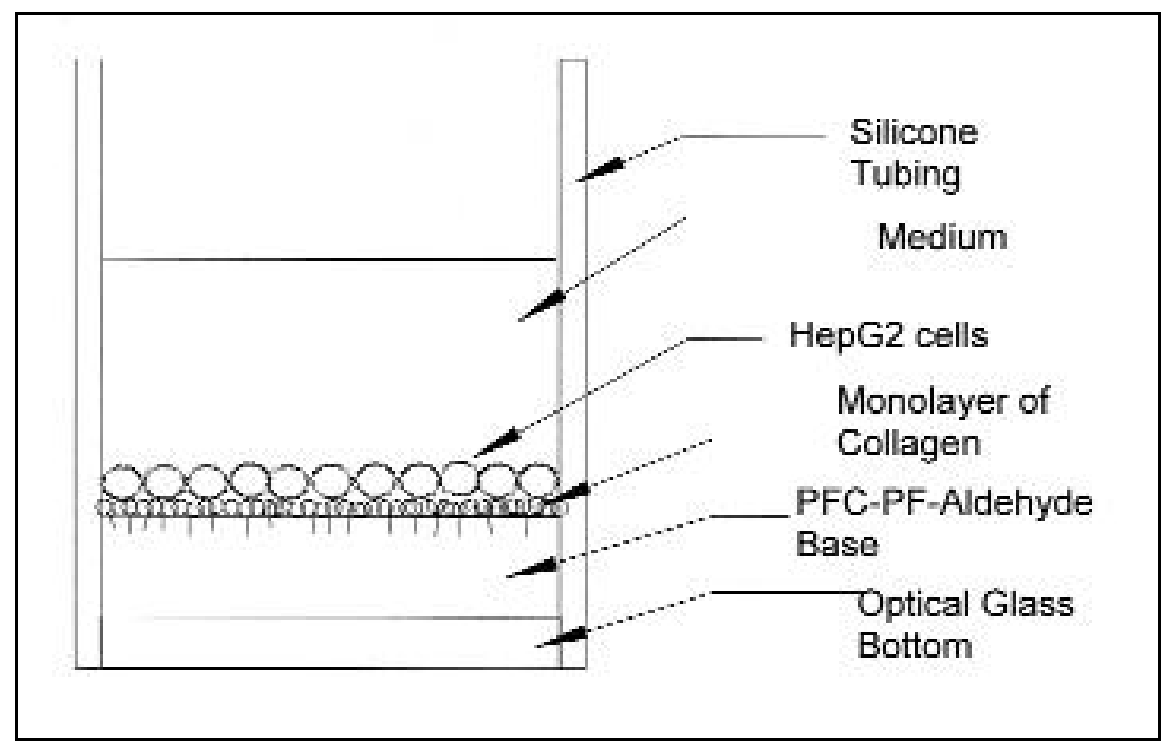

Figure 2. Arrangement of cells in a COPS well grown on a PFC substratum. 
mM pyruvate and $10 \% \mathrm{FBS}$ ) and determine whether the addition of a particular supplement improved growth. The cultures were replenished with fresh media every $48 \mathrm{~h}$. In three separate tests, any factor found to increase the number or quality of the cells surviving after 5-7 days compared to the control was added to the DMEM $^{+}$. This was then used as the control medium for the next experiment in which the cells were seeded at somewhat lower densities. These studies resulted in a medium, $\mathrm{H}$ 2-9, in which $\mathrm{DMEM}^{+}$was supplemented with the following (given in the order detected): insulin $(9 \mathrm{mg} / \mathrm{L})$, epidermal growth factor $(20 \mathrm{ng} / \mathrm{mL})$, transferrin $(5 \mathrm{mg} / \mathrm{L})$, triiodothyronine $(0.3 \mathrm{mg} / \mathrm{L})$, vasopressin $(5 \mu \mathrm{g} / \mathrm{L})$, glutamine $(1.2 \mathrm{~g} / \mathrm{L})$, galactose $(400 \mathrm{mg} / \mathrm{L})$, 2-phosphoascorbate $(0.5 \mathrm{~g} / \mathrm{L})$, phosphoethanolamine $(28 \mathrm{mg} / \mathrm{L})$, putrescine $(0.2 \mathrm{mg} / \mathrm{L})$ vitamin $\mathrm{B}_{12}(1 \mathrm{mg} / \mathrm{L})$, vitamin $\mathrm{E}[0.8 \mathrm{mg} / \mathrm{L}$, dissolved in soybean oil (Sigma)], ergocalciferol (8 $\mu \mathrm{g} / \mathrm{L})$, ergothioneine $(10 \mu \mathrm{g} / \mathrm{L})$, acetylcarnitine $(239 \mathrm{mg} / \mathrm{L})$, acetylcysteine (163 $\mathrm{mg} / \mathrm{L})$, selenium $(6 \mu \mathrm{g} / \mathrm{L}), \mathrm{ZnSO}_{4}(0.7$ $\mathrm{mg} / \mathrm{L}), \mathrm{CuSO}_{4}(50 \mu \mathrm{g} / \mathrm{L})$, and $\mathrm{MnSO}_{4}$ $(2 \mu \mathrm{g} / \mathrm{L})$. These are all normal components of plasma that, in some cases, are present at much higher concentrations than the ones we found to be optimal in this assay system.

In the first experiments, the growth of Hep G2 cells in H 2-9 was compared with that obtained in $\mathrm{DMEM}^{+}$. The cells were seeded at $10^{4}$ cells $/ \mathrm{cm}^{2}$ into two series of $35-\mathrm{mm}$ tissue culture dishes (growth area, $9.5 \mathrm{~cm}^{2}$ ) containing $1 \mathrm{~mL}$ of either $\mathrm{H}$ 2-9 or $\mathrm{DMEM}^{+}$. They were replenished every $48 \mathrm{~h}$ for a period of 10-12 days. The growth was determined at various times by assaying the cultures for an increase in DNA. It was found that although $\mathrm{H} \mathrm{2-9}$ had been found to increase the number of cells surviving in cultures seeded at limiting densities, it did not significantly increase either the rate of growth or the final density of the monolayer cultures, compared to that obtained with $\mathrm{DMEM}^{+}$(data not shown). In contrast, the enriched medium was found to result in a major increase in growth when cells were grown in the COPS plate, compared to that obtained in the dishes. The wells in the COPS plate (growth area, $1.21 \mathrm{~cm}^{2}$ ) and the dishes were seeded in parallel to give a density of $10^{4}$ cells $/ \mathrm{cm}^{2}$ and were provided with 1 $\mathrm{mL} \mathrm{H} \mathrm{2-9.} \mathrm{The} \mathrm{cultures} \mathrm{were} \mathrm{replen-}$ ished every $48 \mathrm{~h}$ during more than three weeks of growth. One of the well cultures and one of the dishes were withdrawn at times indicated and assayed, in duplicate, for DNA and the number of cells determined, using the calibration curve of DNA versus cell number. The variation in the DNA of the duplicate samples was less than $10 \%$. The data in Figure 3 represent the results that we obtained using four different trypsinized suspensions of Hep G2 cells. It is seen that the cells grew nearly three times faster in the COPS plate during the first 12 days than in the dishes. In the dishes, the rate declined markedly after about eight days when the cultures reached confluency at densities of 5-7 $\times 10^{5}$ cells $/ \mathrm{cm}^{2}$, as typically found by others using $\mathrm{DMEM}^{+}(10)$. Although not indicated by the DNA values, the quality of the cells in the dishes declined after the monolayer had formed and, after 10-14 days, they started to retract and detach from the surface. In contrast, the cells in the COPS plate continued to grow beyond the monolayer stage to reach densities nearly 10 times higher than in the dishes. These results show that multilayer growth depends on a higher rate of oxygenation than can be provided in the dishes. They also show that maximum layer formation depends on providing growth factors that are not needed for monolayer growth.

Because the growth of Hep G2 cells has been shown to depend on seeding density (10), the two sets of cultures in these experiments were seeded at the same cell density (e.g., $10^{4}$ cells $/ \mathrm{cm}^{2}$ ). Given the difference in surface areas (9.5 $\mathrm{cm}^{2}$ compared to $\left.1.21 \mathrm{~cm}^{2}\right)$, there were 10 times more cells in the dishes than in the COPS wells. Provided with $1 \mathrm{~mL}$ medium, the cells in the wells were growing with nearly 10 times more medium $/ 10^{4}$ cells than in the dishes. To determine whether this was a factor in promoting multilayer growth, Hep G2 cells were grown in the wells of a 24-well plate (growth area, 2.0 $\mathrm{c} \mathrm{m}^{2}$ ). The wells were seeded with $10^{4}$ cells $/ \mathrm{cm}^{2}$ and provided with $1.5 \mathrm{~mL} \mathrm{H}$ 2-9. It was found that the cells did not grow faster or to higher densities than in dish cultures.

Experiments were done to determine whether the cells growing in the COPS plate continued to secrete albumin and how this compared to the amount secreted in the dish cultures. Both sets of cultures were seeded at a density of $10^{4}$ cells $/ \mathrm{cm}^{2}$ and grown in 1 $\mathrm{mL}$ enriched medium, $\mathrm{H}$ 2-9. The cultures were replenished every $48 \mathrm{~h}$. The amount of albumin secreted into the medium per day was determined at different times over a period of more than 30 days. Samples were taken from the media supernatants just after the cul-

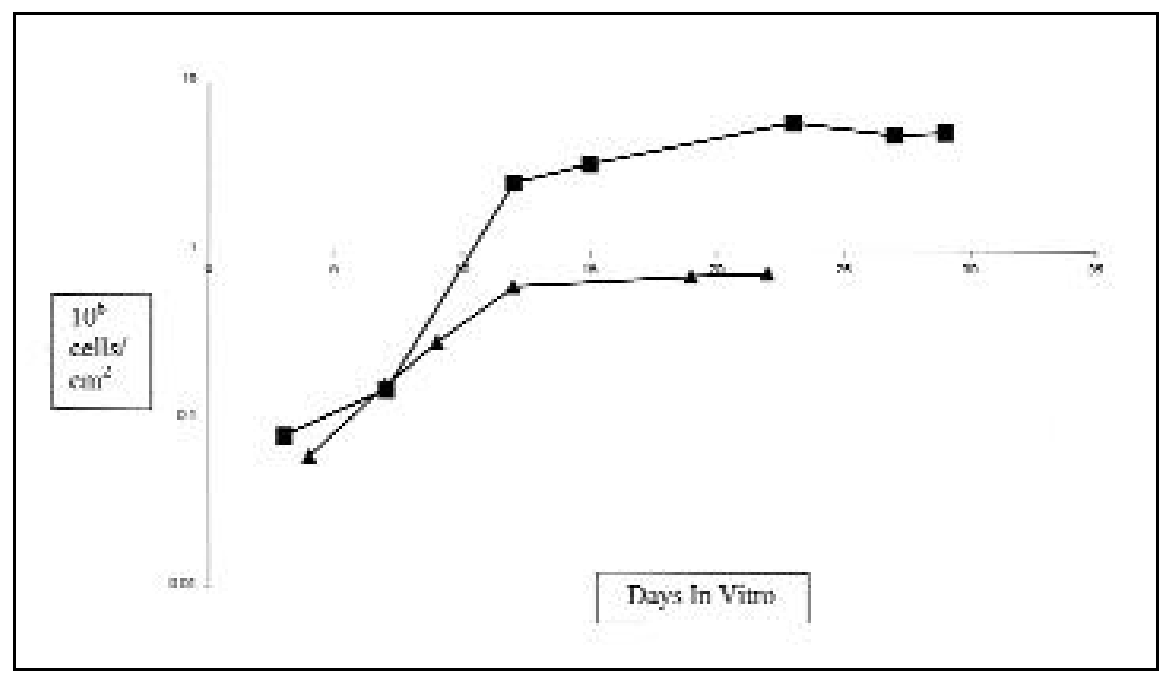

Figure 3. Comparison of the growth of Hep G2 cells in an enriched DMEM+ (H 2-9) in a COPS plate 5 ( $\square$ ) and in 35-mm polystyrene tissue culture dishes $(\triangle)$. Each point is the average of duplicate assays with variation of less than $10 \%$. 
tures were replenished and then $24 \mathrm{~h}$ later, at which time the cell layers were taken for the assay of the DNA. The variation between duplicate assays for albumin was less than $4 \mu \mathrm{g}$, and the variation in the number of cells in the cultures was within $10 \%$. Figure 4 presents the results obtained from seven experiments using five different suspensions of Hep G2 cells. One can see that the albumin secretion in the COPS plate was greater and was maintained longer than in the dishes. The rate in the COPS plate reached a maximum of $50-60 \mu \mathrm{g} / 10^{6}$ cells/day between 15 and 18 days, and this rate was maintained for as long as the cultures were carried. In contrast, in the dish cultures in $\mathrm{H}$ 29, the rate peaked at $30 \mu \mathrm{g} / 10^{6}$ cells/day at 12 days and then declined. However, this was higher than that obtained in dish cultures growing in $\mathrm{DMEM}^{+}$, in which the maximum rate was only about $20 \mu \mathrm{g} / 10^{6}$ cells/day and then declined, as typically found by others (10). The results show that the COPS plate supports both increased density and increased production of albumin on a per-cell basis.

\section{DISCUSSION}

Contact inhibition has come to be regarded as an uncontestable fact of the in vitro life of anchorage-dependent cells. The multilayer growth of Hela, Hep G2, and Vero cells (data not shown) in the COPS plate indicates that, with these cells, contact inhibition is due to inadequate conditions provided in conventional tissue culture systems. The results of these studies also indicate some aspects of the culture conditions that may be required for the 3-D growth of other types of anchorage-dependent cells.

The results indicate that the primary requirement is providing higher and more uniform levels of oxygen to cells than can be provided in conventional tissue culture dishes. Measurements with micro-oxygen electrodes have shown that cells from established cell lines growing in tissue culture dishes are subjected to moderate and, in the case of Hep G2 cells, extreme degrees of hypoxia $(16,24)$. This is because the diffusion of oxygen in growth media is so slow that oxygen in the air cannot reach the cells at the bottom of culture dishes at the rates needed to replenish the oxygen consumed to maintain their normal rates of respiration. This would result in decreased growth and inhibition of respiration-dependent processes. Growth and function of hepatocytes in primary culture would be even more inhibited because these cells take up oxy- gen at more than twice the rate of Hep G2 cells. This suggests that the hypoxic conditions prevailing under conventional culture conditions may be a major factor in the poor survival and dedifferentiation of these cells in vitro. Oxygen is 15-20 times more soluble in PFC than in growth medium. They have been used as oxygen delivery systems to im prove the oxygenation of hypoxic tis- 
sues and increase the growth of cells in tissue culture $(8,13)$. The PFC substratum provides a "head" of oxygen that is delivered to the cells as needed and is automatically replenished by the rapid diffusion of oxygen from air through the silicon walls of the wells. The pericellular oxygen concentration in the cultures has not been determined. It was found that both Hep G2 and Hela cells grew rapidly to densities of 4-6 $\times 10^{6}$ before the rate of growth broke. This indicates that in the COPS plate, open to the air, the oxygen is being delivered at a rate that provides the oxygen these cells need to support respiration and overcome the increase in internal resistance to the diffusion of oxygen as the density increases. It was also found that the capacity of Hep G2 cells to secrete albumin increased during the phase of rapid growth. This indicates that Hep G2 cells can both proliferate and maintain cell-specific functions if they are provided with adequate levels of oxygen. In contrast, the results from studies of monolayer cultures have indicated that proliferation and differentiation are reciprocally related (19).

Bader et al. (2) have shown that primary rat hepatocytes cultured on gaspermeable membranes express many enzymes that cannot be detected in cultures grown in polystyrene dishes.
They propose that aerobic mechanisms are suppressed during growth in monolayers. Our findings confirm this and further suggest that multilayer growth is the result of up-regulation of aerobic mechanisms caused by an increase in the amount of oxygen provided in a COPS plate.

The maximum growth of multilayers was also found to depend on using greatly enriched media compared to those usually used for monolayer cultures. It was found quite early that multilayer growth required serum, which could not be replaced by any of the many factors tested. The addition of various hormones, growth factors, and metabolites to the serum-supplemented DMEM was found to result in a consistent increase in the final density of the cells and the amount of albumin secreted. The active factors are all known to play a role in respiration or in respiration-dependent processes that would be required for optimal growth and maintenance of differentiated functions. Of particular interest was the finding that a mixture of antioxidants, including vitamin E, 2-phosphoascorbate, acetylcysteine, and ergothioneine, was required. Each of these, tested individually, has been shown to protect against reactive oxygen species $(1,20)$ that are known to increase as respiration increases (4). Antioxidants may

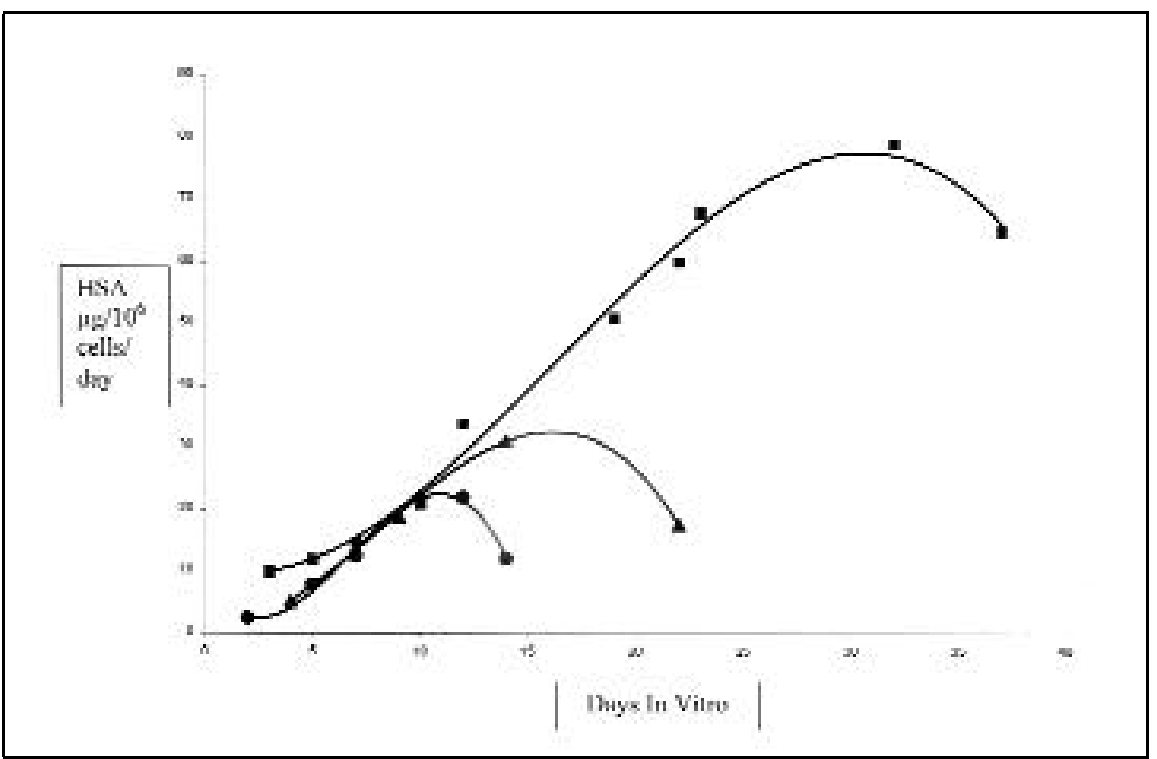

Figure 4. Comparison of albumin secretion by Hep G2 cells in enriched medium (H 2-9) in a COPS plate $5(\square)$, polystyrene tissue culture dishes $(\bullet)$, and polystyrene dishes with $\operatorname{DMEM}^{+}(\bullet)$. Data for (匹) were obtained on five different suspensions. Values are averages of duplicate samples with a total variation of less than $10 \%$. Trendlines were fitted to each curve with a third-degree polynomial expression.

be required in this system, as in vivo, to regulate the production of, and prevent damage from, free radicals.

Increased oxygenation and an enriched medium do not completely explain why or how cells round up and grow over and on top of each other instead of remaining flat and spread out on the surface, limiting growth to a monolayer. It has been found that, when cells are prevented from attaching to a surface, they adhere to each other, form ing spheroids. The proliferation of cells in spheroids is limited by poor diffusion of oxygen $(5,17,18)$, but the synthesis of cell-specific proteins and matrix materials may increase $(9,14)$. Spheroid formation suggests the potential strength of the forces binding cells to each other when aggregated and also that these are much weaker than the forces produced by adhesion to tissue culture plastic. This results in the cells adhering preferentially and more strongly to plastic substrata instead of to each other, form ing aggregates. Multilayer growth can be explained as the result of a situation where there is a better balance between the forces produced by intercellular bonding and those produced on adhesion to the PFC substratum. This may be because of the very different way in which cells attach to plastic and to a PFC-based substratum. The adhesion to plastic is the result of cells seeking out and making multiple contacts with fixed sites on the substratum not only preferentially to desorbed matrix factors but also to many adventitious sites on the plastics. This results in very strong adhesion, caused by cooperative effects, in which one half of the cell surface is confined to a rigid substratum. This would severely limit the interaction of cells with each other. Cells do not adhere to uncoated PFC $(11,12,21)$. They can adhere only to collagen moieties that have been coupled, via their free amino groups, to a PF-aldehyde whose perfluorinated carbon chain sinks into and anchors the cell-collagen complexes to the PFC. This provides a very specific but relatively weak adhesion, commandeering less of the cell surface than on adhesion to plastics. In view of the liquid nature of PFCs, the collagen sites would have a degree of mobility, and cell surface receptors would also have a degree of freedom that could promote interac- 
tion between cells. Cells adhering to a coated PFC surface are in a much more dynamic interfacial situation that provides more cellular options, both mechanically and biochemically, than when spread out flat on plastic. Given a substratum that also provides the high level of oxygen needed to support growth, cells could round up and grow over each other and, using the matrix factors they may produce or that may be provided in serum, grow over and on top of each other to form multilayers.

This analysis suggests that multilayer growth depends on the concurrence of three conditions provided uniquely in the COPS. It depends on providing higher and more uniform levels of oxygen than those available in conventional tissue culture systems. It also depends on providing a nutrient medium that can meet the metabolic demands of a more active aerobic metabolism than that maintained in monolayer cultures. Finally, it depends on providing a com pliant substratum that allows cells to round up and form contacts with each other. Each of these conditions can be experimentally modified, and their relative importance for $3-D$ growth can be determined. Such studies may result in the development of systems that can support 3-D growth of other types of anchorage-dependent cells. This would be important in many areas of clinical research and basic cell science.

\section{ACKNOWLEDGMENTS}

Funding for this research was provided by the Experimental Engineering Station Development Fund and by a grant from the University of Utah Research Fund.

\section{REFERENCES}

1.Asmos, K.K. and P.L. Perdersen. 1988. Functional significance of mitochondrial bound oxidation of ergothioneine and analogues investigated by pulse radiolysis: reoxyreactions involving ergothioneine and vitamin C. Biochem. J. 315:625-629.

2.Bader, A., N. Fruhauf, M. Tiedge, M. Drinkgern, L. DeBartolo, J.T. Borlak, G. Steinhoff, and A. Haveric. 1999. Enhanced oxygen delivery reverses anaerobic metabolic states in prolonged sandwich rat hepatocyte culture. Exp. Cell Res. 246:221-232.
3.Bouma, M.-E., N. Rogier, C. Verthier, C. Labarre, and G. Feldman. 1989. Further investigation of the human hepatoblastoma derived cell line, Hep G2: morphology and im munocytochemical studies of hepatic secreted proteins. In Vitro Cell. Dev. Biol. 25:267-275.

4.Chance, B. 1965. Energy linked pyridine nucleotide reduction: effect of hyperbolic oxygen in vitro. Nature 206:257-260.

5.Freyer, J.O. and R.M. Suntherland. 1986. Regulation and growth saturation and development of necrosis in EMT 6/RO multicellular spheroids by glucose and oxygen supply. Cancer Res. 46:3504-3512.

6.Giaever, L. and C.R. Keese. 1983. Behavior of cells at liquid interfaces. Proc. Natl. Acad. Sci. USA 80:219-222.

7.Ireland, R.E. and I. Longbin. 1993. An im proved procedure for preparation of the DessMartin periodinase. J. Org. Chem. 58:28892893.

8.Ju, L.K. and W.B. Arminger. 1992. Use of perfluorocarbon emulsions in cell culture. BioTechniques 12:253-263.

9.Karakusa, F. and Y. Sawaski. 1996. The restoration of functions in serially passaged calf hepatocytes by spheroid formation. In Vitro Cell. Dev. Biol. Anim. 32:30-37.

10.Keese, C.R. and I. Giaever. 1983. Cell growth on liquid interfaces: role of surface active compounds. Proc. Natl. Acad. Sci. USA 80:5622-5627.

11.Kelly, J.H. and G. Darington. 1989. Modulation of liver-specific phenotype in human hepatoblastoma line Hep G2. In Vitro Cell Dev. Biol. 25:217-222.

12.Keese, C.R. and I. Giaever. 1983. Cell growth on liquid microcarriers. Science 219:1448-144.

13.King, A.T., B.J. Mulligan, and K.C. Lowe. 1989. Perfluorocarbons for gas transport and improvement of cell cultures. BioTechniques 7:1037-1042.

14.Koide, N., T.Y. Shanji, K. Asano, M. Kawaushi, K. Spagushi, Y. Koide, and Y.M. Mori. 1989. Continuous high albumin production by multicellular spheroids of adult rat hepatocytes formed in presence of liver-derived proteoglycans. Biochem. Biophys. Res. Commun. 161:385-391.

15.Labarca, C.K. and K. Paigen. 1980. A sim ple, rapid, and sensitive DNA assay procedure. Anal. Biochem. 102:344-352.

16.Metzen, E.M., M. Wolff, J. Fandrey, and W. Jelkman. 1991. Pericellular $\mathrm{pO}_{2}$ and $\mathrm{O}_{2}$ consumption in monolayers. Respir. Physiol. 100:101-110.

17.Mueller-Kleiser, W. 1984. Methods for determining oxygen consumption rates and diffusion coefficients in multicellular spheroids. Biophys. J. 46:343-348.

18.Mueller-Kleiser, W. 1989. Multicellular spheroids: a review on cellular aggregates in cancer research. J. Cancer Res. Clin. Oncol. 111:101-122.

19.Nakamura, T., K. Yoshimoto, and Y. Ichihara. 1983. Reciprocal modulation of growth and differential functions of mature rat hepatocytes in primary culture by cell-cell contact and cell membranes. Proc. Natl. Acad. Sci. USA 80:7229-7233.

20.Packer, L., S. Roy, and C.K. Sen. 1997.
Lipoic acid: a metabolic anti-oxidant and potential red-ox modulator of transcription. Adv. Pharmacol. 38:79-101.

21.Rappaport, C., L.-F. Soong, and E.M. Trujillo. 1996. Novel oxygenation system supports multilayer growth of Hela cells. BioTechniques 21:801-818.

22. Trujillo, E.M. and C. Rappaport, inventors. The University of Utah, assignee. 1997. Im proved oxygenation of anchorage dependent mammalian cells using perfluorocarbons. US patent no. 5702989 .

23. Wessler, F., R. Iltis, and L.C. Clark, Jr. 1977. The solubility of oxygen in highly fluorinized liquids. J. Fluoro. Chem. 9:137-146.

24. Wolff, M., J. Fandrey, and J. Jelkman. 1993. Microelectrode measurements of pericellular $\mathrm{pO}_{2}$ in erythropoietin producing hepatoma cell culture. Am. J. Physiol. 264:12661270.

Received 25 October 2000; accepted 1 June 2001.

\section{Address correspondence to:}

Dr. Catherine Rappaport

Department of Chemical and Fuels Engineering University of Utah

Salt Lake City, UT 84112, USA

e-mail:rappapor@eng.utah.edu 